\title{
Additional corpus biopsy enhances the detection of Helicobacter pylori infection in a background of gastritis with atrophy
}

\author{
Hung-Chieh Lan ${ }^{1,3}$, Tseng-Shing Chen ${ }^{1 *}$, Anna Fen-Yau Li ${ }^{2}$, Full-Young Chang ${ }^{1}$ and Han-Chieh Lin ${ }^{1}$
}

\begin{abstract}
Background: The best sites for biopsy-based tests to evaluate H. pylori infection in gastritis with atrophy are not well known. This study aimed to evaluate the site and sensitivity of biopsy-based tests in terms of degree of gastritis with atrophy.

Methods: One hundred and sixty-four (164) uninvestigated dyspepsia patients were enrolled. Biopsy-based tests (i.e., culture, histology Giemsa stain and rapid urease test) and non-invasive tests (anti-H. pylori lgG) were performed. The gold standard of H. pylori infection was defined according to previous criteria. The sensitivity, specificity, positive predictive rate and negative predictive rate of biopsy-based tests at the gastric antrum and body were calculated in terms of degree of gastritis with atrophy.

Results: The prevalence rate of $\mathrm{H}$. pylori infection in the 164 patients was $63.4 \%$. Gastritis with atrophy was significantly higher at the antrum than at the body (76\% vs. 31\%; $p<0.001)$. The sensitivity of biopsy-based test decreased when the degree of gastritis with atrophy increased regardless of biopsy site (for normal, mild, moderate, and severe gastritis with atrophy, the sensitivity of histology Giemsa stain was 100\%, 100\%, 88\%, and 66\%, respectively, and $100 \%, 97 \%, 91 \%$, and $66 \%$, respectively, for rapid urease test). In moderate to severe antrum or body gastritis with atrophy, additional corpus biopsy resulted in increased sensitivity to $16.67 \%$ compare to single antrum biopsy.
\end{abstract}

Conclusions: In moderate to severe gastritis with atrophy, biopsy-based test should include the corpus for avoiding false negative results.

Keywords: Gastritis with atrophy, Biopsy-based test, Biopsy site, Helicobacter pylori

\section{Background}

Helicobacter pylori (H. pylori) and gastritis with atrophy are both risk factors for gastric cancer [1]. Around onethird of infected patients are estimated to have gastritis with atrophy [2] and the regression of these preneoplasm lesions may occur after successful eradication [3-5]. As such, H. pylori eradication in patients with gastritis with atrophy is recommended by current guidelines $[1,6,7]$.

Although eradication is essential for this group of patients, the accurate identification of $H$. pylori against

\footnotetext{
* Correspondence: tschen@vghtpe.gov.tw

'Division of Gastroenterology, Department of Medicine, Taipei Veterans General Hospital and National Yang-Ming University, \#201 Shih-Pai Road, Section 2, Taipei, Taiwan, ROC

Full list of author information is available at the end of the article
}

a background of gastritis with atrophy remains difficult [8]. False negative results occur even under more reliable H. pylori diagnostic tests like histology Giemsa stain [9]. False negative status, or the so-called sampling error, may result from patchy bacterial colonization through the stomach and altered distribution because of gastritis with atrophy and intestinal metaplasia. Thus, it is important to set a recommended biopsy site.

The updated Sydney Classification had set the gold standard for gastric biopsy more than 10 years ago [10]. According to this Classification, five biopsy sites should be collected: one specimen each should be obtained from the lesser and the greater curvature of the antrum, both within $2-3 \mathrm{~cm}$ form the pylorus; from the lesser curvature of the corpus about $4 \mathrm{~cm}$ proximal to the 
angulus; from the middle portion of the greater curvature of the corpus, approximately $8 \mathrm{~cm}$ from the cardia; and one from incisura angularis. However, for the consideration of patient's comfort and operator's convenience, this kind of extensive approach is uncommon in our daily practice. Studies on the most practical biopsy site for diagnosing $H$. pylori infection have conflicting results. Antrum biopsy is recommended by Genta et al. [11] while others recommend at least one corpus biopsy [12,13]. Hazell et al. and Woo et al. found it necessary to take both antral and corpus biopsies $[14,15]$. According to current guidelines, there is no optimal site when performing a biopsy-based test in a general condition, much less in those with gastritis with atrophy [16].

It is suggested that as gastritis with atrophy progresses, the mid corpus is the last area involved and is the last "lodgeable" mucosa for $H$. pylori in the stomach $[17,18]$. Additional corpus biopsy is suggested in these situations [12] but the exact additional benefit is not well known.

This prospectively designed study used the combination method as gold standard to investigate the correlation among sensitivity of biopsy-based test, biopsy location, degree of gastritis with atrophy, and $H$. pylori prevalence rate.

\section{Methods}

\section{Patient population}

Dyspeptic patients scheduled for upper gastrointestinal endoscopy were recruited. Patients with any of the following conditions were excluded: (1) ulcer complications (e.g., bleeding, stenosis, or perforation); (2) previous stomach surgery; (3) gastric neoplasms; (4) use of any substituted benzimidazoles and bismuth-containing preparations within the last 7 days prior to the start of the study; (5) past or current treatment with anti-H. pylori therapy; or (6) severe systemic diseases. All patients provided prior informed consent and received invasive and non-invasive tests for $H$. pylori. The local Ethics Committee on Human Test approved the study.

\section{Endoscopy and biopsy sampling}

According to the updated Sydney system, the biopsy sampling protocol required that more than five biopsy samples were obtained: two from the antral mucosa; one from the mucosa of the angularis incisura; two from the oxyntic area. For the consideration of patients' comfort and operator's convenience, we modified this recommendation. Two biopsy sites with multiple biopsies were applied to our endoscopy biopsy protocol. Three sets of biopsy specimens each from the greater curvature of the mid-body and lesser curvature of the antrum near the incisura were obtained during endoscopy for urease, histologic, and culture tests.

\section{Rapid urease test}

One biopsy from the greater curvature of the mid-body and one from the lesser curvature near the incisura were obtained for the urease test (CLO test; Delta West, Bentley, Australia). Antral and body biopsy specimens were evaluated separately, and the test was considered positive when the color changed from orange to pink within 24 hours.

\section{Histologic evaluation of the biopsy samples}

Biopsy specimens from the antrum and the body were fixed in formalin and assessed for the presence of $H$. pylori by a modified Giemsa stain, and for the degree of inflammatory cell infiltration, atrophy, and intestinal metaplasia by hematoxylin and eosin staining. The antrum and body histologic features of gastric mucosa were graded according to the updated Sydney System (0, none; 1 , mild; 2 , moderate; and 3 , severe) [10]. In addition, the degree of gastritis activity was evaluated in Giemsa-negative patients with positive for either rapid urease test or serology. Also, the activity of gastritis was recorded according to the updated Sydney System. (1-4 points with 1 representing "normal", 2 to 4 representing "mildly, moderately and markedly active gastritis", respectively). Those who got two or more points on the pathological review were regarded as active gastritis which is an indirect sign of $H$. pylori infection. An experienced pathologist (Anna Fen-Yau Li) who was blinded to the results of other tests for $H$. pylori evaluated all histologic sections.

\section{Culture}

In culture, the biopsy sample was homogenized with 0.3 $\mathrm{mL}$ broth, plated on chocolate agar, and incubated at $37^{\circ} \mathrm{C}$ in a micro-aerobic $\left(15 \% \mathrm{CO}_{2}\right.$ and $\left.5 \% \mathrm{O}_{2}\right)$ incubator until the colony appeared, which was usually 3 days. The negative plates were kept for 7 days. The growth of $H$. pylori was confirmed by the characteristic morphology (Gram-negative and curved) and positive catalase, oxidase, and urease reactions observed.

\section{Serologic evaluation}

Serum specimens were tested for the presence of IgG antibodies against $H$. pylori using a quantitative ELISA test (HEL-pTEST II; AMRAD, Kew, Australia) according to the manufacturer's instructions. A specimen was considered positive if it contained $>50$ units $/ \mathrm{mL}$ and negative if it contained $\leq 50$ units $/ \mathrm{mL}$. 


\section{Serum pepsinogen levels}

For serology studies, blood was drawn immediately after endoscopy and collected and stored at $-70^{\circ} \mathrm{C}$ until assay. Fasting serum Pepsinogen I was measured in all patients by radioimmunoassay (Pepsik; Sorin Biomedica, Saluggia, Italy) according to the manufacturer's instructions, while basal Pepsinogen II levels were determined using a specific enzyme immunoassay (BIOHIT Plc, Helsinki, Finland).

\section{Gold standard definition}

To define the gold standard of active $H$. pylori infection, we modified the approach used by Shin et al. before [8]. A patient was classified as current $H$. pylori infection based on either a positive culture or, in the case of a negative culture, both positive histology and positive urease test (Group A). A patient was classified as $H$. pylori-negative when the culture, histologic examination, urease test, and serology were all negative (Group E). When either the histologic examination (Giemsa stain or presence of active gastritis) or urease test was positive, the results were classified based on the results of serology test. When IgG antibodies to $H$. pylori were detected, the results were considered "probably positive" (Group B). When IgG antibodies were not detected, the results were regarded as being "probably negative" (Group C). When a patient was serologically positive but negative on all biopsy-based tests, this was interpreted as either a past $H$. pylori infection or a false-positive result and the patient was classified as negative for current $H$. pylori infection (Group D). Groups A and B were defined as gold standard positive while Groups C, D, and E were gold standard negative.

\section{Statistical analysis}

Standard methods were used to calculate the sensitivity, specificity, and positive and negative predictive values, their 95\% confidence intervals, and their test validity. Chi-square tests were used to compare variables (i.e., number of cases who had moderate-to-marked gastritis with atrophy at the antrum and corpus). To examine the decreasing trend in the prevalence of histology, as influenced by the severity of glandular atrophy, chi-square test for trend was applied. All statistical analyses and database collection were performed using the Statistical Package for Social Sciences (SPSS 17.0 for Windows, SPSS. Inc., Chicago, IL, USA).

\section{Results}

\section{Subjects characteristics}

A total of 164 patients were enrolled in this study. Regardless of the biopsy site, a total of 328 biopsy specimens were received for histologic evaluation (Figure 1).

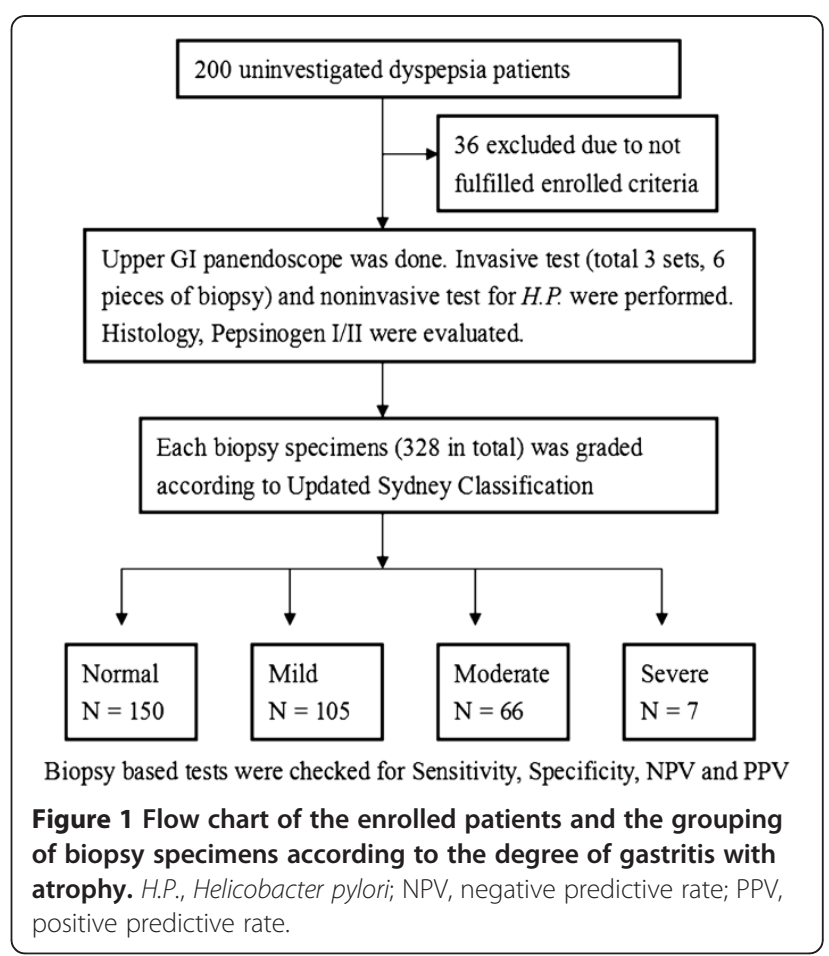

Using the pre-defined gold standard, the results of the four diagnostic tests for detecting current $H$. pylori infection in all subjects $(n=164)$ were shown in Figure 2. Culture was positive in 87 patients. Among the patients who were culture negative, 16 were positive for both

\begin{tabular}{|c|c|c|c|c|c|c|}
\hline $\begin{array}{l}\text { H. pylori } \\
\text { culture }\end{array}$ & CLO & Histology & $\begin{array}{c}\text { Active } \\
\text { gastritis }\end{array}$ & Serology & $\begin{array}{c}\text { No. } \\
\text { patients }\end{array}$ & Group \\
\hline+ & + & + & & + & 72 & \\
\hline+ & + & + & & - & 15 & \\
\hline+ & - & + & & + & 0 & \\
\hline+ & + & - & & + & 0 & \\
\hline+ & - & - & & + & 0 & A \\
\hline+ & - & - & & - & 0 & \\
\hline - & + & + & & + & 14 & \\
\hline - & + & + & & - & 2 & \\
\hline - & + & - & & + & 1 & - \\
\hline - & - & + & & + & 0 & \\
\hline - & + & - & + & - & 0 & B \\
\hline - & - & - & + & + & 0 & \\
\hline - & + & - & - & - & 0 & \\
\hline - & - & + & & - & 0 & C \\
\hline - & - & - & - & + & 2 & D \\
\hline - & - & - & & - & 58 & $\mathrm{E}$ \\
\hline Total & & & & & 164 & \\
\hline \multicolumn{7}{|c|}{$\begin{array}{l}\text { Figure } 2 \text { Diagnostic tests for Helicobacter pylori detection: } \\
\text { Group A, definitely positive ( } n=103) \text {; Group B, probably positive } \\
(n=1) \text {; Group C, probably negative ( } n=0) \text {; Group D, past H. pylori } \\
\text { infection or false positive ( } n=2) \text {; Group } E \text {, definitely negative }(n=58) \text {; } \\
\text { CLO, indicates rapid urease test on biopsy specimens; Histology, } \\
\text { refers to } H \text {. pylori positive based on modified Giemsa staining; } \\
\text { Active gastritis, refers to presence or absence of active gastritis } \\
\text { (an indirect sign of active } H \text {. pylori infection). }\end{array}$} \\
\hline
\end{tabular}


the CLOtest and histology. These 103 patients were regarded as true positives (Group A). Moreover, one patient was positive on serology and positive on either the CLOtest or histology testing (Giemsa stain or presence of active gastritis), so this patient was classified as probably $H$. pylori positive (Group B). No patient was positive for a single biopsy-based test, so there was no probably negative patient (Group C). Two patients were positive on serology only (with titers of $67 \mathrm{unit} / \mathrm{ml}$ and 171 unit/ml, respectively). Their gastritis activity of the biopsy specimens were reviewed again. None of them showed active gastritis in the pathological review (both of them got 1 point at their antrum and body biopsy specimens). They were considered either a past $H$. pylori infection or a false positive (Group D). Fifty-eight patients were negative on all tests and were considered true negative (Group E).

When Groups A and B were considered as $H$. pylori positive and groups $\mathrm{C}, \mathrm{D}$, and $\mathrm{E}$ as $H$. pylori negative, the patients' characteristics, including numbers of $H$. pylori infection, mean ratio of Pepsinogen I/II, and numbers of peptic ulcer and gastritis with atrophy were shown in Table 1 . The overall $H$. pylori infection rate was $63.4 \%$ and the mean Pepsinogen I/II ratio was 2.37. According to Updated Sydney Classification, 50 patients (31.5\%) had moderate-to-severe antrum gastritis with atrophy, and $23(14.0 \%)$ had moderate-to-severe body gastritis with atrophy. Compared to the body, the antrum had significantly higher percentage of gastritis with atrophy (Figure 3). The antrum also had significantly higher percentage of intestinal metaplasia (antrum 11.6\% vs. body $0 \%, p<0.001)$.

\section{Sensitivity of biopsy based tests and degree of gastritis of atrophy}

Regardless of biopsy site, the biopsy specimens $(n=328)$ were grouped according to the degree of gastritis with atrophy. Of these, 208 specimens were collected from the "defined infection" patients (Groups A and B). In these biopsy specimens, 101 had normal histology while 70 had mild, 34 had moderate, and 3 had severe gastritis with atrophy. The sensitivity of histology Giemsa stain and rapid urease test in these specimens were evaluated (Figure 4) As the degree of gastritis with atrophy progressed, the sensitivities of these two biopsy-based test decreased (sensitivity of histology Giemsa stain in normal, mild, moderate, and severe gastritis with atrophy was $100 \%, 100 \%, 88 \%$, and $66 \%$, respectively, while the sensitivity of rapid urease test was $100 \%, 97 \%, 91 \%$, and $66 \%$, respectively).

\section{Sensitivity of biopsy based tests and biopsy sites}

Using the pre-defined gold standard, the sensitivities and specificities of the diagnostic tests, depending on
Table 1 Demographic characteristics of patients $(n=164)$

\begin{tabular}{|c|c|c|}
\hline Age-year, mean (range) & 43.51 & $(20-70)$ \\
\hline \multicolumn{3}{|l|}{ Gender-no. (\%) } \\
\hline Male & 85 & $(51.8)$ \\
\hline Female & 79 & $(48.2)$ \\
\hline \multicolumn{3}{|l|}{ Pgl/Pgll ratio (range) } \\
\hline -Mean & 2.37 & $(0.46-11.51)$ \\
\hline \multicolumn{3}{|l|}{ H. pylori status } \\
\hline Infection & 104 & $(63.4)$ \\
\hline Non-infection & 60 & $(36.6)$ \\
\hline \multicolumn{3}{|l|}{ Total histology } \\
\hline \multicolumn{3}{|c|}{ specimens and H. pylori status } \\
\hline Infection & 208 & $(63.4)$ \\
\hline Non infection & 120 & $(36.6)$ \\
\hline \multicolumn{3}{|l|}{ Peptic ulcer, no. (\%) } \\
\hline GU & 7 & $(4.2)$ \\
\hline DU & 53 & $(32.3)$ \\
\hline \multicolumn{3}{|c|}{ Antrum gastritis with atrophy } \\
\hline Normal to mild & 114 & $(69.5)$ \\
\hline Moderate to severe & 50 & $(31.5)$ \\
\hline \multicolumn{3}{|l|}{ Body gastritis with atrophy } \\
\hline Normal to mild & 141 & $(86.0)$ \\
\hline Moderate to severe & 23 & $(14.0)$ \\
\hline \multicolumn{3}{|l|}{ Antrum intestinal metaplasia } \\
\hline Normal & 145 & $(88.4)$ \\
\hline Intestinal metaplasia & 19 & $(11.6)$ \\
\hline \multicolumn{3}{|l|}{ Body intestinal metaplasia } \\
\hline Normal & 164 & $(100.0)$ \\
\hline Intestinal metaplasia & 0 & $(0)$ \\
\hline
\end{tabular}

grade of antrum and body atrophy, were presented in Tables 2 and 3. In moderate to severe antrum gastritis with atrophy $(\mathrm{n}=50)$, single antrum biopsy for CLOtest yielded fair sensitivity (84\%; 95\% CI: 63.08-94.75\%), which was lower than single body biopsy or combination of body and antrum (100\%; 95\% CI: 83.42-100\%). There was a similar finding in histology (sensitivity of single antrum biopsy, $84 \%$ vs. $96 \%$ in single body biopsy or combination of body and antrum). However, when the degree of antrum gastritis with atrophy was normalto-mild, the sensitivity of both biopsy-based tests, regardless of biopsy site, was between $97.47 \%$ and $100 \%$ (Table 2).

In moderate-to-severe body gastritis with atrophy $(\mathrm{n}=23)$, single antrum biopsy for CLOtest yielded fair sensitivity (83.33\%; 95\% CI: 50.88-97.06\%), which was lower than single body biopsy or combination of body and antrum (100\%; 95\% CI: 69.87-100\%). A similar finding was found in histology Giemsa stain (sensitivity of 


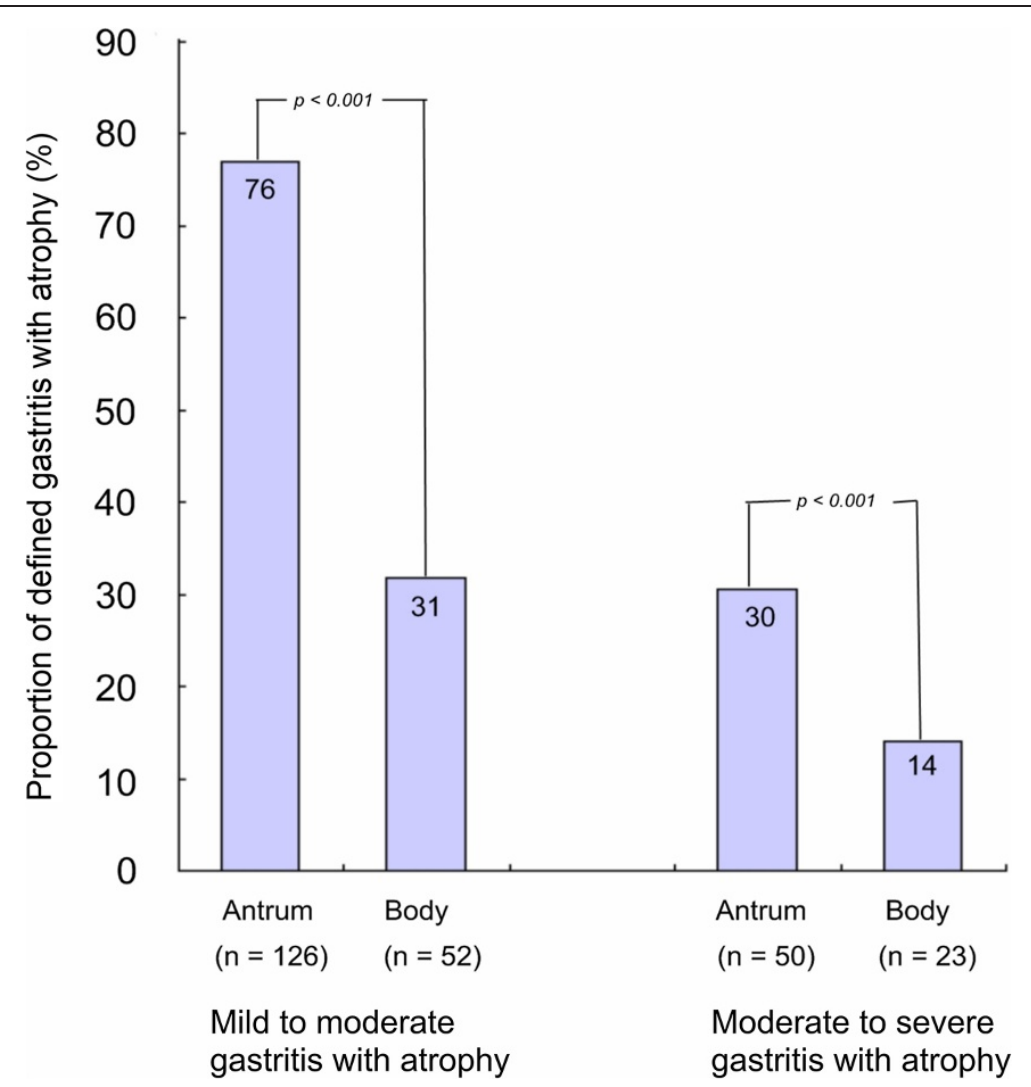

Figure 3 The proportion of mild-severe and moderate-severe gastritis with atrophy based on biopsy site. The $p$ value was calculated using the chi-square test.

single antrum biopsy, $83.33 \%$ vs. $91.67 \%$ in single body biopsy or combination of body and antrum). However, when the degree of body gastritis with atrophy was normal to mild ( $\mathrm{n}=141)$, the sensitivity of both biopsy based tests, regardless of biopsy site, was between $95.66 \%$ and $100 \%$ (Table 3).

The prevalence rate of $H$. pylori infection between normal, mild, moderate, and severe gastritis with atrophy were evaluated. As the degree of gastritis with atrophy increased, the prevalence rate of $H$. pylori infection decreased (Figure 5). As the degree of antrum gastritis with atrophy increased, the prevalence rate of $H$. pylori infection decreased significantly ( $p=0.027$; chisquare test for trends). A similar trend was found in body gastritis with atrophy, with a trend of decreasing $H$. pylori infection rate $(p=0.216)$.

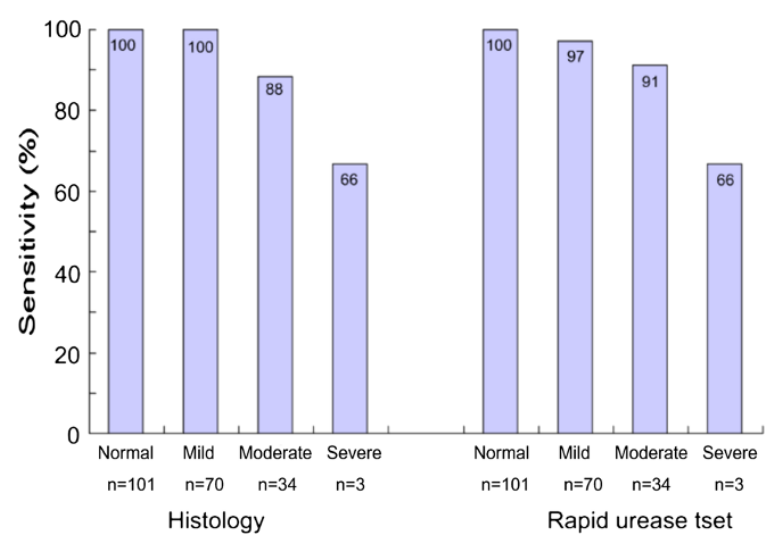

Figure 4 The sensitivity of biopsy-based tests (histology Giemsa stain and rapid urease test) according to grade of mucosal atrophy. 
Table $2 \mathrm{H}$. pylori sensitivity and specificity depending on the grade of antrum gastritis with atrophy

\begin{tabular}{|c|c|c|}
\hline Ca degree of gastritis with atrophy at antrum & Normal to mild & Moderate to severe \\
\hline$n=164$ & $\mathrm{n}=114$ & $\mathrm{n}=50$ \\
\hline \multicolumn{3}{|l|}{ CLOtest Antrum } \\
\hline Sensitivity & $97.47(90.31-99.56)$ & $84.00(63.08-94.75)$ \\
\hline Specificity & $100.00(87.68-100.00)$ & $100.00(83.42-100.00)$ \\
\hline PPV & $100.00(94.08-100.00)$ & $100.00(80.76-100.00)$ \\
\hline NPV & $94.59(80.47-99.06)$ & $86.20(67.43-95.49)$ \\
\hline Accuracy & 98.25 & \\
\hline \multicolumn{3}{|l|}{ CLOtest Body } \\
\hline Sensitivity & $100.00(94.22-100.00)$ & $100.00(83.42-100.00)$ \\
\hline Specificity & $100.00(87.68-100.00)$ & $100.00(83.42-100.00)$ \\
\hline PPV & $100.00(94.22-100.00)$ & $100.00(83.42-100.00)$ \\
\hline NPV & $100.00(87.68-100.00)$ & $100.00(83.42-100.00)$ \\
\hline Accuracy & 100.00 & 100.00 \\
\hline \multicolumn{3}{|l|}{ CLOtest Antrum + Body } \\
\hline Sensitivity & $100.00(94.22-100.00)$ & $100.00(83.42-100.00)$ \\
\hline Specificity & $100.00(87.68-100.00)$ & $100.00(83.42-100.00)$ \\
\hline PPV & $100.00(94.22-100.00)$ & $100.00(83.42-100.00)$ \\
\hline NPV & $100.00(87.68-100.00)$ & $100.00(83.42-100.00)$ \\
\hline Accuracy & 100.00 & 100.00 \\
\hline \multicolumn{3}{|l|}{ Histology Antrum } \\
\hline Sensitivity & 98.73 (92.18-99.93) & 84.00 (63.08-94.75) \\
\hline Specificity & $100.00(87.68-100.00)$ & $100.00(83.42-100.00)$ \\
\hline PPV & $100.00(94.15-100.00)$ & $100.00(80.76-100.00)$ \\
\hline NPV & 97.22 (83.80-99.85) & $86.20(67.43-95.49)$ \\
\hline Accuracy & 99.12 & 92.00 \\
\hline \multicolumn{3}{|l|}{ Histology Body } \\
\hline Sensitivity & $100.00(94.22-100.00)$ & $96.00(77.68-99.79)$ \\
\hline Specificity & $100.00(87.68-100.00)$ & $100.00(83.42-100.00)$ \\
\hline PPV & $100.00(94.22-100.00)$ & $100.00(82.83-100.00)$ \\
\hline NPV & $100.00(87.68-100.00)$ & 96.15 (78.42-99.80) \\
\hline Accuracy & 100.00 & 98.00 \\
\hline \multicolumn{3}{|l|}{ Histology Antrum + Body } \\
\hline Sensitivity & $100.00(94.22-100.00)$ & $96.00(77.68-99.79)$ \\
\hline Specificity & $100.00(87.68-100.00)$ & $100.00(83.42-100.00)$ \\
\hline PPV & $100.00(94.22-100.00)$ & $100.00(82.83-100.00)$ \\
\hline NPV & $100.00(87.68-100.00)$ & 96.15 (78.42-99.80) \\
\hline Accuracy & 100.00 & 98.00 \\
\hline
\end{tabular}

\section{Discussion}

Biopsy-based tests are important diagnostic tools for $H$. pylori. However, the optimal biopsy site is still unknown, especially in cases of gastritis with atrophy. Current guidelines only recommend combining antrum and body biopsies for rapid urease test in the circumstance of antibiotics or proton pump inhibitors exposure. Sampling from the angularis, corpus, and antrum for histology was ever suggested in the same situation [16]. Reviewing recent studies, there is little practical information about the adequate biopsy numbers and suitable biopsy sites. Single and multiple specimens at the antrum alone, at the 
Table $3 \mathbf{H}$. pylori sensitivity and specificity depending on grade of body gastritis with atrophy

\begin{tabular}{|c|c|c|}
\hline Ca degree of gastritis with atrophy at body & Normal to mild & Moderate to severe \\
\hline$n=164$ & $\mathrm{n}=141$ & $\mathrm{n}=\mathbf{2 3}$ \\
\hline \multicolumn{3}{|l|}{ CLOtest Antrum } \\
\hline Sensitivity & $95.66(88.62-98.60)$ & $83.33(50.88-97.06)$ \\
\hline Specificity & $100.00(90.94-100.00)$ & $100.00(67.86-100.00)$ \\
\hline PPV & $100.00(94.79-100.00)$ & $100.00(65.55-100.00)$ \\
\hline NPV & $92.45(80.93-97.55)$ & $84.61(53.66-97.29)$ \\
\hline Accuracy & 97.16 & 91.30 \\
\hline \multicolumn{3}{|l|}{ CLOtest Body } \\
\hline Sensitivity & $100.00(95.00-100.00)$ & $100.00(69.87-100.00)$ \\
\hline Specificity & $100.00(90.94-100.00)$ & $100.00(67.85-100.00)$ \\
\hline PPV & $100.00(95.00-100.00)$ & $100.00(69.87-100.00)$ \\
\hline NPV & $100.00(90.94-100.00)$ & $100.00(67.85-100.00)$ \\
\hline Accuracy & 100.00 & 100.00 \\
\hline \multicolumn{3}{|l|}{ CLOtest Antrum + Body } \\
\hline Sensitivity & $100.00(95.00-100.00)$ & $100.00(69.87-100.00)$ \\
\hline Specificity & $100.00(90.94-100.00)$ & $100.00(67.85-100.00)$ \\
\hline PPV & $100.00(95.00-100.00)$ & $100.00(69.87-100.00)$ \\
\hline NPV & $100.00(90.94-100.00)$ & $100.00(67.85-100.00)$ \\
\hline Accuracy & 100.00 & 100.00 \\
\hline \multicolumn{3}{|l|}{ Histology Antrum } \\
\hline Sensitivity & 96.74 (90.09-99.15) & 83.33 (50.88-97.06) \\
\hline Specificity & $100.00(90.94-100.00)$ & $100.00(67.86-100.00)$ \\
\hline PPV & $100.00(94.84-100.00)$ & $100.00(65.55-100.00)$ \\
\hline NPV & $94.23(83.08-98.50)$ & $84.61(53.66-97.29)$ \\
\hline Accuracy & 97.87 & 91.30 \\
\hline \multicolumn{3}{|l|}{ Histology Body } \\
\hline Sensitivity & $100.00(95.00-100.00)$ & 91.67 (59.75-99.56) \\
\hline Specificity & $100.00(90.94-100.00)$ & $100.00(67.86-100.00)$ \\
\hline PPV & $100.00(95.00-100.00)$ & $100.00(67.86-100.00)$ \\
\hline NPV & $100.00(90.94-100.00)$ & 91.67 (59.75-99.56) \\
\hline Accuracy & 100.00 & 95.65 \\
\hline \multicolumn{3}{|l|}{ Histology Antrum + Body } \\
\hline Sensitivity & $100.00(95.00-100.00)$ & 91.67 (59.75-99.56) \\
\hline Specificity & $100.00(90.94-100.00)$ & $100.00(67.86-100.00)$ \\
\hline PPV & $100.00(95.00-100.00)$ & $100.00(67.86-100.00)$ \\
\hline NPV & $100.00(90.94-100.00)$ & $91.67(59.75-99.56)$ \\
\hline Accuracy & 100.00 & 95.65 \\
\hline
\end{tabular}

body alone, or in combination of antrum and body had been described and applied (Table 4). These diagnostic approaches seem largely arbitrarily $[8,16,19-28]$. In order to clarify the exact benefit of these biopsy sites, a gold standard is necessary.

In 2009, Shin et al. modified $H$. pylori diagnostic methods and set a validated gold standard according to combination tests results [8]. Since the combination method is the preferred approach in patients with gastritis with atrophy, the defined gold standard may best correlate with active $H$. pylori infection. Our study follows this approach to determine the best biopsy site with highest sensitivity against a background of gastritis with atrophy. 


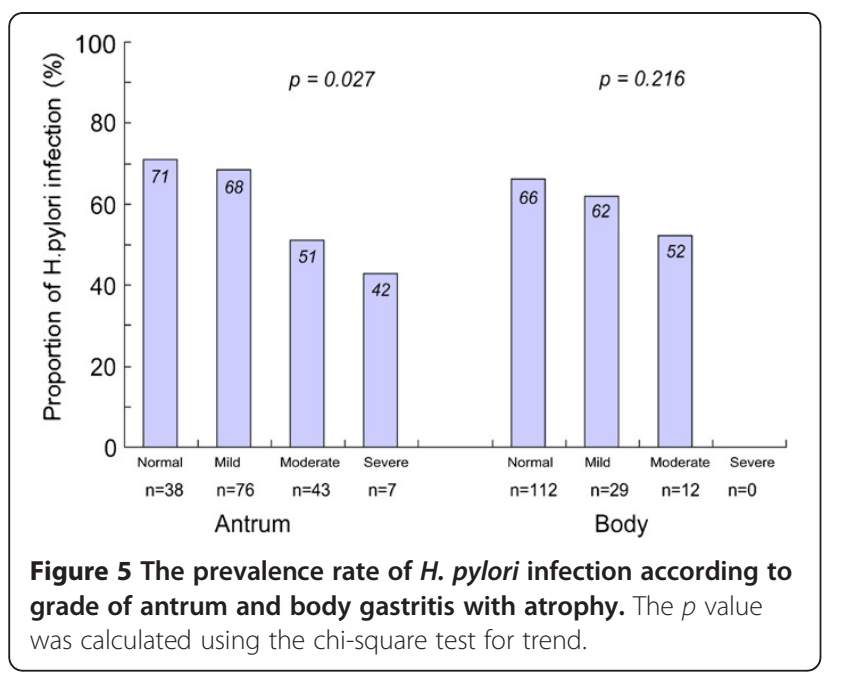

The present study has several findings. First, making a biopsy at the antrum increases the risk of obtaining atrophic gastric mucosa, which is associated higher frequency of false negative results. Second, when body gastritis with atrophy develops, antrum atrophy exists already. Third, antrum biopsy alone has decreased sensitivity when there is moderate-to-severe antrum gastritis with atrophy (CLOtest up to 16\% and histology up to $12 \%$ ) and moderate-to-severe body gastritis with atrophy (CLOtest up to $16.67 \%$ and histology up to $8.34 \%)$.

First, the frequency of antrum gastritis with atrophy is higher than that of the body. This is consistent with previous studies $[22,29]$. It is believed that gastritis with atrophy progresses from the antrum initially and extends to the body in the advanced stage $[12,17,18]$. Thus, the prevalence rate of antrum gastritis with atrophy is significantly higher than that of the body. As such, taking a biopsy at the antrum may yield higher chances of atrophic gastric mucosa than taking one from the body.

Regardless of biopsy site, if the degree of gastritis with atrophy in each specimen is considered, sensitivity decreases as the severity of gastritis with atrophy progresses (Figure 3). This is similar to the findings of Kim et al. [22]. These false negative subjects could be proven to be $H$. pylori infected after combining with other diagnostic methods. Such phenomenon is explained by the increasing rate of sampling error as gastritis with atrophy progresses [29]. Thus, biopsy at antrum increases the risk of getting atrophic gastric mucosa that is associated with higher frequency of false negatives.

Second, applying the aforementioned conclusion on biopsy site and on the degree of gastritis with atrophy, it is interesting to find an opposite results between antrum atrophy and body atrophy. Theoretically, biopsy site at the atrophic area yields poorer sensitivity so single antrum biopsy done in antrum atrophy subjects results in less sensitivity. However, this principle does not apply in single body biopsy performed in body atrophy cases. Instead, the present study reveals a general rule that antrum biopsy results in lower sensitivity in either antrum or body atrophy. This is because when body gastritis with atrophy occurs, antrum atrophy exists already $[17,18,29]$. In fact, most of the patients here with

Table 4 Studies on the diagnostic tests of $H$. pylori and the respective biopsy sites chosen, published between November 2005 and February 2011

\begin{tabular}{|c|c|c|c|c|c|c|}
\hline Authors & $\begin{array}{l}\text { Country and } \\
\text { population studied }\end{array}$ & $\begin{array}{l}\text { Sampling site of } \\
\text { Histology stain }\end{array}$ & $\begin{array}{l}\text { Sampling site of } \\
\text { Rapid urease test }\end{array}$ & $\begin{array}{l}\text { Age range of } \\
\text { subjects (years) }\end{array}$ & $\begin{array}{l}\text { Numbers of } \\
\text { subjects }\end{array}$ & $\begin{array}{l}\text { Numbers of } H . \\
\text { pylori-positive \% }\end{array}$ \\
\hline Choi et al. [22] & $\begin{array}{l}\text { Korea, health check-up } \\
\text { examinees }\end{array}$ & $* 1 \mathrm{LA} 1 \mathrm{LB}$ & $1 \mathrm{LA}$ & Mean 47.8 & 515 & 53.2 \\
\hline Hsu et al. [23] & Taiwan, dyspepsia & - & 1LA vs. 1LA1GB & Mean 55.0-57.8 & 355 & 33.5 \\
\hline Vaira et al. [24] & Italy, dyspepsia & $2 \mathrm{~A}$ & $2 \mathrm{~A}$ & Median 52 & 1000 & 45.3 \\
\hline Goh et al. [25] & Malaysia, dyspepsia & $1 \mathrm{~A} 1 \mathrm{~B}$ & $1 \mathrm{~A} 1 \mathrm{~B}$ & Mean 50.7 & 206 & 53.9 \\
\hline Shin et al. [8] & Korea, gastritis with atrophy & $2 \mathrm{~A} 2 \mathrm{~B}$ & $1 \mathrm{~A} 1 \mathrm{~B}$ & Mean 57.7 & 651 & 41.2 \\
\hline Siddique et al. [26] & Kuwait, endoscopy evaluation & - & $1 \mathrm{~A}$ vs. $2 \mathrm{~A}$ vs. $3 \mathrm{~A}$ vs. $4 \mathrm{~A}$ & Mean 36.1 & 100 & - \\
\hline Yoo et al. [21] & Korea, dyspepsia & $2 \mathrm{~A} 2 \mathrm{~B}$ & 1LA1LB & Mean 56.8 & 430 & - \\
\hline Yakoob et al. [27] & Pakistan, dyspepsia & $2 \mathrm{~A}$ & $2 \mathrm{~A}$ & Mean 43 & 109 & 57.0 \\
\hline Kim et al. [28] & Korea, gastric cancer & 2LA2LB2GB & $1 \mathrm{~GB}$ & Median 61 & 194 & 84.0 \\
\hline Tang et al. [29] & Taiwan, bleeding & $2 \mathrm{~B} 2 \mathrm{U}$ & $2 \mathrm{~A}$ & Mean 63.5 & 324 & 53.7 \\
\hline $\begin{array}{l}\text { Roma-Giannikou } \\
\text { et al. [30] }\end{array}$ & Greece & $1 \mathrm{~A}$ & $1 \mathrm{~A}$ & Mean 10.4 & 254 & - \\
\hline Chey et al. [15] & Guideline & 1GA1GB1Ag & 1AgB1GA & - & - & - \\
\hline
\end{tabular}

${ }^{*} 1 \mathrm{~A}$, one piece from the antrum; $1 \mathrm{~B}$, one piece from the body; $2 \mathrm{~A} 2 \mathrm{~B}$, two pieces from the antrum and 2 from the body; $1 \mathrm{LA}$, one piece from the lesser curvature of the antrum; $1 \mathrm{LB}$, one piece from the lesser curvature of the body; $1 \mathrm{GA}$, one piece from the great curvature of the antrum; $1 \mathrm{~GB}$, one piece from the great curvature of the body; $1 \mathrm{AgB}$, one piece from the body angularis; $2 \mathrm{U}$, two pieces from the ulcer margin. 
moderate-to-severe body atrophy $(\mathrm{n}=23)$ also have moderate-to-severe antrum atrophy (20/23).

Third, single body biopsy discloses an increased sensitivity as compared with single antrum biopsy in a background of moderate-to-severe antrum gastritis with atrophy (CLOtest up to $16 \%$ and histology up to $12 \%)$. Similar finding is founded when corpus biopsy is taken in moderate-to-severe body gastritis with atrophy (with a increased sensitivity in CLOtest up to 16.67\% and histology up to $8.34 \%$ ). In contrast, single antrum and single corpus has comparable sensitivity when gastritis with atrophy is normal-to-mild (CLOtest 97.47-95.66 and histology 96.74-98.73). Poor colonization of H. pylori in the atrophic mucosa and intestinal metaplasia have been well discussed $[9,12]$. When performing biopsybased test in a background of gastritis with atrophy, sampling errors, insufficient bacterial load [9], bacterial migration, bacterial clearance [12], bacterial patchy distribution, and poor mucosal colonization in areas of intestinal metaplasia are common causes of false negative results. Furthermore, as the gastritis with atrophy progresses, the prevalence of $H$. pylori infection decreases. Single specimen sampling at the antrum may miss this relative small but risky patients. And this approach may miss those who could get benefit from eradication. Therefore, the present study recommends additional corpus biopsy to avoid false negative results in moderateto-severe gastritis with atrophy.

This study has several potential limitations. First, it was conducted in a $H$. pylori endemic area, such that the interpretation and application of the study results should consider the local $H$. pylori prevalence rate. Second, in evaluating gastritis with atrophy by histology, the sampling method used was based on the modified Updated Sydney Classification. The latest approach method to evaluate gastritis with atrophy is OLGA staging, which is composed of multiple antrum and body biopsy specimens [30]. The average grade of antrum and body gastritis with atrophy in these specimens was evaluated while staging was based on the degree and extent of gastritis with atrophy. In this study, only one piece at the antrum and one at the body was used to represent the whole antrum and body mucosal condition. This may be inadequate. However, compared to histology, non-invasive methods like Pepsinogen I/II ratio also disclosed lower values in moderate-to-severe gastritis with atrophy (mean Pepsinogen I/II ratio, 1.96 in moderate-to-severe antrum gastritis with atrophy and 1.79 in moderate-to-severe body gastritis with atrophy). This may eliminate the concern of inadequate sampling in the present study. Third, though we used visual analogue scale to score the gastritis with atrophy, grading of antrum atrophy is most difficult for pathologists since kappa values are very low and this wound be our limitation [10].

\section{Conclusion}

Biopsy-based test should include corpus specimen in cases of moderate-to-severe gastritis with atrophy to avoid false negative results.

\section{Abbreviations}

H. pylori: Helicobacter pylori.

\section{Competing interests}

The authors have no potential conflicts (financial, professional, or personal).

\section{Authors' contributions}

HC Lin, TS Chen and HC Lan designed the project. TS Chen, FY Chang and AFY Lee performed the experiments. HC Lan wrote the manuscript. TS Chen and HC Lan contributed to the discussion of the data and the revision of the manuscript. All readers read and approved the final manuscript.

\section{Authors' information}

Writing Assistance: Gene Alzona Nisperos, MD.

\section{Acknowledgments}

This study was supported by the Taiwan Otsuka Pharmaceutical Company Ltd.

\section{Author details}

'Division of Gastroenterology, Department of Medicine, Taipei Veterans General Hospital and National Yang-Ming University, \#201 Shih-Pai Road, Section 2, Taipei, Taiwan, ROC. ${ }^{2}$ Department of Pathology and Laboratory Medicine, Taipei Veterans General Hospital and National Yang-Ming University, Taipei, Taiwan, ROC. ${ }^{3}$ Division of General Medicine, Department of Medicine, Taipei City Hospital, Taipei, Taiwan, ROC.

Received: 2 July 2012 Accepted: 13 December 2012

Published: 29 December 2012

\section{References}

1. Malfertheiner P, Megraud F, O'Morain CA, Atherton J, Axon AT, Bazzoli F, Gensini GF, Gisbert JP, Graham DY, Rokkas T, El-Omar EM, Kuipers EJ: Management of Helicobacter pylori infection-the Maastricht IV/ Florence Consensus Report. Gut 2012, 61:646-664.

2. Kuipers EJ, Uyterlinde AM, Pena AS, Roosendaal R, Pals G, Nelis GF, Festen HP, Meuwissen SG: Long-term sequelae of Helicobacter pylori gastritis. Lancet 1995, 345:1525-1528.

3. Ito M, Haruma K, Kamada T, Mihara M, Kim S, Kitadai Y, Sumii M, Tanaka S, Yoshihara M, Chayama K: Helicobacter pylori eradication therapy improves atrophic gastritis and intestinal metaplasia: a 5 -year prospective study of patients with atrophic gastritis. Aliment Pharmacol Ther 2002, 16:1449-1456.

4. Ohkusa T, Fujiki K, Takashimizu I, Kumagai J, Tanizawa T, Eishi Y, Yokoyama T, Watanabe M: Improvement in atrophic gastritis and intestinal metaplasia in patients in whom Helicobacter pylori was eradicated. Ann Intern Med 2001, 134:380-386.

5. Rokkas T, Pistiolas D, Sechopoulos P, Robotis I, Margantinis G: The longterm impact of Helicobacter pylori eradication on gastric histology: a systematic review and meta-analysis. Helicobacter 2007, 12(Suppl2):32-38.

6. Malfertheiner P, Megraud F, O'Morain C, Bazzoli F, El-Omar E, Graham D, Hunt R, Rokkas T, Vakil N, Kuipers EJ: Current concepts in the management of Helicobacter pylori infection: the Maastricht III Consensus Report. Gut 2007, 56:772-781.

7. Malfertheiner P, Megraud F, O'Morain C, Hungin AP, Jones R, Axon A, Graham DY, Tytgat G: Current concepts in the management of Helicobacter pylori infection-the Maastricht 2-2000 Consensus Report. Aliment Pharmacol Ther 2002, 16:167-180.

8. Shin CM, Kim N, Lee HS, Lee HE, Lee SH, Park YS, Hwang JH, Kim JW, Jeong SH, Lee DH, Jung HC, Song IS: Validation of diagnostic tests for Helicobacter pylori with regard to grade of atrophic gastritis and/or intestinal metaplasia. Helicobacter 2009, 14:512-519.

9. Korstanje A, van Eeden S, Offerhaus GJ, Sabbe L, den Hartog G, Biemond I, Lamers CB: The 13-carbon urea breath test for the diagnosis of 
Helicobacter pylori infection in subjects with atrophic gastritis: evaluation in a primary care setting. Aliment Pharmacol Ther 2006, 24:643-650.

10. Dixon MF, Genta RM, Yardley JH, Correa P: Classification and grading of gastritis. The updated Sydney system. International workshop on the histopathology of gastritis, Houston 1994. Am J Surg Pathol 1996, 20:1161-1181.

11. Genta RM, Graham DY: Comparison of biopsy sites for the histopathologic diagnosis of Helicobacter pylori: a topographic study of H. pylori density and distribution. Gastrointest Endosc 1994, 40:342-345.

12. Satoh K, Kimura K, Taniguchi Y, Kihira K, Takimoto T, Saifuku K, Kawata H, Tokumaru K, Kojima T, Seki M, Ido K, Fujioka T: Biopsy sites suitable for the diagnosis of Helicobacter pylori infection and the assessment of the extent of atrophic gastritis. Am J Gastroenterol 1998, 93:569-573.

13. Van IMC, Laheij RJ, de Boer WA, Jansen JB: The importance of corpus biopsies for the determination of Helicobacter pylori infection. Neth J Med 2005, 63:141-145.

14. Hazell SL, Hennessy WB, Borody TJ, Carrick J, Ralston M, Brady L, Lee A: Campylobacter pyloridis gastritis II: distribution of bacteria and associated inflammation in the gastro-duodenal environment. Am J Gastroenterol 1987, 82:297-301.

15. Woo JS, El-Zimaity HM, Genta RM, Yousfi MM, Graham DY: The best gastric site for obtaining a positive rapid urease test. Helicobacter 1996, 1:256-259.

16. Chey WD, Wong BC: American college of gastroenterology guideline on the management of helicobacter pylori infection. Am J Gastroenterol 2007, 102:1808-1825.

17. Correa P: Chronic gastritis: a clinico-pathological classification. Am J Gastroenterol 1988, 83:504-509.

18. Kimura K: Chronological transition of the fundic-pyloric border determined by step-wise biopsy of the lesser and greater curvatures of the stomach. Gastroenterology 1972, 63:584-592.

19. Choi J, Kim CH, Kim D, Chung SJ, Song JH, Kang JM, Yang JI, Park MJ, Kim YS, Yim JY, Lim SH, Kim JS, Jung HC, Song IS: Prospective evaluation of a new stool antigen test for the detection of Helicobacter pylori, in comparison with histology, rapid urease test, (13)C-urea breath test, and serology. J Gastroenterol Hepatol 2011, 26:1053-1059.

20. Goh KL, Cheah PL, Navaratnam P, Chin SC, Xiao SD: HUITAI rapid urease test: a new ultra-rapid biopsy urease test for the diagnosis of Helicobacter pylori infection. J Dig Dis 2007, 8:139-142.

21. Hsu WH, Wang SS, Kuo CH, Chen CY, Chang CW, Hu HM, Wang JY, Yang YC, Lin YC, Wang WM, Wu DC, Wu MT, Kuo FC: Dual specimens increase the diagnostic accuracy and reduce the reaction duration of rapid urease test. World J Gastroenterol 2010, 16(23):2926-2930.

22. Kim CG, Choi IJ, Lee JY, Cho SJ, Nam BH, Kook MC, Hong EK, Kim YW: Biopsy site for detecting Helicobacter pylori infection in patients with gastric cancer. J Gastroenterol Hepatol 2009, 24:469-474.

23. Roma-Giannikou E, Roubani A, Sgouras DN, Panayiotou J, Van-Vliet C, Polyzos A, Roka K, Daikos G: Endoscopic tests for the diagnosis of helicobacter pylori infection in children: validation of rapid urease test. Helicobacter 2010, 15:227-232.

24. Siddique I, Al-Mekhaizeem K, Alateeqi N, Memon A, Hasan F: Diagnosis of Helicobacter pylori improving the sensitivity of CLOtest by increasing the number of gastric antral biopsies: J Clin Gastroenterol 2008, 42:356-360.

25. Tang JH, Liu NJ, Cheng HT, Lee CS, Chu YY, Sung KF, Lin CH, Tsou YK, Lien $J M$, Cheng CL: Endoscopic diagnosis of Helicobacter pylori infection by rapid urease test in bleeding peptic ulcers: a prospective case-control study. J Clin Gastroenterol 2009, 43:133-139.

26. Vaira D, Vakil N, Gatta L, Ricci C, Perna F, Saracino I, Fiorini G, Holton J: Accuracy of a new ultrafast rapid urease test to diagnose Helicobacter pylori infection in 1000 consecutive dyspeptic patients. Aliment Pharmacol Ther 2010, 31:331-338.

27. Yakoob J, Jafri W, Abid S, Jafri N, Abbas Z, Hamid S, Islam M, Anis K, Shah $\mathrm{HA}$, Shaikh H: Role of rapid urease test and histopathology in the diagnosis of Helicobacter pylori infection in a developing country. BMC Gastroenterol 2005, 5:38.

28. Yoo JY, Kim N, Park YS, Hwang JH, Kim JW, Jeong SH, Lee HS, Choe C, Lee $\mathrm{DH}$, Jung HC, Song IS: Detection rate of Helicobacter pylori against a background of atrophic gastritis and/or intestinal metaplasia. J Clin Gastroenterol 2007, 41:751-755.
29. Kang HY, Kim N, Park YS, Hwang JH, Kim JW, Jeong SH, Lee DH, Jung HC, Song IS: Progression of atrophic gastritis and intestinal metaplasia drives Helicobacter pylori out of the gastric mucosa. Dig Dis Sci 2006, 51:2310-2315.

30. Rugge M, Meggio A, Pennelli G, Piscioli F, Giacomelli L, De Pretis G, Graham DY: Gastritis staging in clinical practice: the OLGA staging system. Gut 2007, 56:631-636.

doi:10.1186/1471-230X-12-182

Cite this article as: Lan et al:: Additional corpus biopsy enhances the detection of Helicobacter pylori infection in a background of gastritis with atrophy. BMC Gastroenterology 2012 12:182.

\section{Submit your next manuscript to BioMed Central and take full advantage of:}

- Convenient online submission

- Thorough peer review

- No space constraints or color figure charges

- Immediate publication on acceptance

- Inclusion in PubMed, CAS, Scopus and Google Scholar

- Research which is freely available for redistribution 